\title{
Prevalence of diabetic retinopathy in patients in a tertiary hospital in south India
}

\author{
T. Jayalekshmi ${ }^{1}$, K.P. Poulose ${ }^{2}$ \\ ${ }^{1}$ Dr T Jayalekshmi, Associate professor, SUT Academy of medical sciences, Vattappara, Trivandrum, Kerala, India, \\ ${ }^{2}$ Prof K P Poulose, Professor emeritus of medicine, SUT Academy of medical sciences, Vattappara, Trivandrum, Kerala, \\ India
}

Address for correspondence: Dr T Jayalekshmi, Email: t_jayalekshmi@yahoo.com

\begin{abstract}
Aims: To estimate the prevalence of Retinopathy in patients attending a diabetic clinic and to evaluate the risk factors underlying its development. Methods: 750 diabetic patients who reported for executive check up in a preventive clinic were evaluated for absence or presence of retinopathy. Diabetic Retinopathy (DR) present was graded as non proliferative diabetic retinopathy (NPDR) and proliferative diabetic retinopathy (PDR). Risk factors were then evaluated in order to delineate those related to retinopathy. Investigations included complete blood count, blood sugar, serum lipids, ECG, Renal function tests and complete clinical examination. Results: DR was detected in 111 patients (14.8\%) with NPDR in 106 patients $(14.1 \%)$ and PDR in 5 patients $(0.7 \%)$. Factors related to the incidence of retinopathy were duration of diabetes, presence of hypertension, high blood sugar level and hyperlipidemia. It was found that duration of diabetes, level of glycemic control and high levels of cholesterol were statistically significant for the occurrence of retinopathy. Conclusion: In addition to glycemic control, lowering of serum lipids may be effective in lowering the incidence of retinopathy in diabetic patients.Hypertension was not related to the occurrence of retinopathy.
\end{abstract}

Keywords: Diabetic Retinopathy, Prevalence, Risk factors

\section{Introduction}

Diabetic Retinopathy is the leading cause of blindness in middle aged adults [1]. According to WHO 70 million people were affected by diabetes in India in the year 2015 and the figure is estimated to rise to 79.4 million by $2030[2]$. It is estimated that the global magnitude of DR will increase from 126.6 million in 2010 to 191 million by 2030. Present review shows that prevalence of DR in India and China is significantly lower [3]. The reported prevalence of DR in India ranges from $17.6 \%$ to $28.2 \%$ [4]. A recent Meta analysis of 35 population based studies of Diabetes worldwide indicated that about one third of diabetic individuals had some degree of DR, and fewer than $10 \%$ had either diabetic macular oedema (DME) or PDR. This means that a substantial number of individuals with underlying diabetes do not progress to overt vision threatening DR if managed properly.

Manuscript received $20^{\text {th }}$ September 2016

Reviewed: $30^{\text {th }}$ September 2016

Author Corrected: $09^{\text {th }}$ October 2016

Accepted for Publication $18^{\text {th }}$ October 2016
However these are at a risk of conversion and need regular follow up [4].

\section{Materials and Methods}

750 diabetic patients who reported for executive check up over a period of 2 years were examined in ophthalmology department of Sut hospital for the presence or absence of DR. A full medical history was taken including age of patient, duration of diabetes, treatment details, history of hypertension, and hyperlipidemia. Fasting blood glucose of each patient was estimated after an overnight fast. Diabetic control was graded as Normal ( $<100 \mathrm{mg} / \mathrm{dl})$, Moderate control (100-126 mg/dl), and High (>126 mg/dl). Glycosylated hemoglobin assay was not done in all cases and hence not included in this study. Hypertension was deemed to be present when the systolic blood pressure was $>140$ $\mathrm{mm} \mathrm{Hg}$ or when diastolic blood pressure was $>90 \mathrm{~mm}$ $\mathrm{Hg}$ or when patient gave history of hypertension controlled with medications. Hyperlipidemia was 
graded as present when total cholesterol was >200 $\mathrm{mg} / \mathrm{dl}$ or when patient was on medication for hyperlipidemia. The pupil of each eye was dilated using Tropicamide $1 \%$ and phenylephrine $10 \%$ eye drops followed by detailed fundus examination with direct and indirect ophthalmoscopy. DR patients were classified according to the grading in the worse eye.
Statistical Analysis- Quantitative variables were expressed in mean ${ }^{+} /-$standard deviation (SD) and categorical variables expressed in percentage. Association of retinopathy with selected variables was carried out using chi-square test. SPSS 17.0 version was used for analysis. $\mathrm{P}$ value less than 0.05 was considered statistically significant.

\section{Results}

Of the 750 diabetic patients, 567(75.6\%) were males and 183(24.4\%) were females. The mean age of those examined was ${ }^{+} /-$SD $53.9^{+} /-9.1$ [Table 1$]$.

Table-1: Percentage distribution of the sample according to age

\begin{tabular}{|l|l|l|}
\hline Age & Count & Percent \\
\hline $31-40$ & 50 & 6.7 \\
\hline $41-50$ & 219 & 29.2 \\
\hline $51-60$ & 295 & 39.3 \\
\hline $61-70$ & 158 & 21.1 \\
\hline $71-80$ & 28 & 3.7 \\
\hline Mean \pm SD & $53.9 \pm 9.1$ & \\
\hline
\end{tabular}

Family history of diabetes was present in 551 patients (73.5\%) with higher incidence in mother 340(45.3\%) and siblings $370(49.3 \%)$ and lower incidence in father 255(34.0 \%). [Table 2]. DR was detected in 111(14.8\%) patients. Of this Non proliferative DR (NPDR) was present in $106(14.1 \%)$ and Proliferative DR (PDR) in $5(0.7 \%)$ [Table 3]

Table-2: Percentage distribution of the sample according to family history

\begin{tabular}{|l|l|l|}
\hline Family history & Count & Percent \\
\hline Father & 255 & 34.0 \\
\hline Mother & 340 & 45.3 \\
\hline Siblings & 370 & 49.3 \\
\hline Both parents & 151 & 20.1 \\
\hline Parents + siblings & 119 & 15.9 \\
\hline
\end{tabular}

Table-3: Percentage distribution of the sample according to associated retinopathy

\begin{tabular}{|l|l|l|}
\hline Associated retinopathy & Count & Percent \\
\hline Normal & 639 & 85.2 \\
\hline NPDR & 106 & 14.1 \\
\hline PDR & 5 & 0.7 \\
\hline
\end{tabular}

Table 4: Comparison of treatment based on retinopathy

\begin{tabular}{|l|l|l|l|l|l|l|}
\hline \multirow{3}{*}{ Treatment } & \multicolumn{2}{|l|}{ Retinopathy } & \multirow{2}{*}{ Abnormal } & \multirow{2}{*}{$\chi^{\mathbf{2}}$} & \multirow{2}{*}{ p } \\
\cline { 2 - 5 } & Normal & Percent & Count & Percent & & \\
\cline { 2 - 5 } & Count & 88.2 & 72 & 11.8 & \multirow{2}{*}{$23.15^{* *}$} & 0.001 \\
\hline OHA & 536 & 76.7 & 10 & 23.3 & & \\
\hline OHAlin only & 33 & 70.7 & 29 & 29.3 & \\
\hline
\end{tabular}

**: - Significant at 0.01 level 
Overall, retinopathy was more prevalent in patients with Insulin requiring diabetes 39(52.6\%) compared to patients not requiring insulin $72(11.8 \%)$. [Table 4$]$.

The highest risk for development of DR was in those patients having diabetes for $>10$ years. There was significant association between duration of diabetes and DR. [Table 5].

Table-5: Comparison of retinopathy based on duration

\begin{tabular}{|c|c|c|c|c|c|c|}
\hline \multirow{3}{*}{ Duration } & \multicolumn{4}{|c|}{ Retinopathy } & \multirow{3}{*}{$\chi^{2}$} & \multirow{3}{*}{$\mathbf{p}$} \\
\hline & \multicolumn{2}{|c|}{ Normal } & \multicolumn{2}{|c|}{ Abnormal } & & \\
\hline & Count & Percent & Count & Percent & & \\
\hline $0-5$ & 288 & 94.7 & 16 & 5.3 & \multirow{5}{*}{$55.27 * *$} & \multirow{5}{*}{$\mathrm{p}<0.01$} \\
\hline $6-10$ & 174 & 84.1 & 33 & 15.9 & & \\
\hline $11-15$ & 85 & 78.0 & 24 & 22.0 & & \\
\hline $16-20$ & 55 & 64.7 & 30 & 35.3 & & \\
\hline$>20$ & 37 & 82.2 & 8 & 17.8 & & \\
\hline
\end{tabular}

**: - Significant at 0.01 level

A total of 349(46.5\%) with diabetes had associated hypertension and of this 52(14.9\%) patients had DR. There was no significant association between DR and hypertension in this study [Table 6].

Table-6: Comparison of HT based on retinopathy

\begin{tabular}{|c|c|c|c|c|c|c|}
\hline \multirow{3}{*}{ HT } & \multicolumn{4}{|c|}{ Retinopathy } & \multirow{3}{*}{$\chi^{2}$} & \multirow{3}{*}{$\mathbf{p}$} \\
\hline & \multicolumn{2}{|c|}{ Normal } & \multicolumn{2}{|c|}{ Abnormal } & & \\
\hline & Count & Percent & Count & Percent & & \\
\hline Yes & 297 & 85.1 & 52 & 14.9 & \multirow{2}{*}{0.01} & \multirow{2}{*}{0.943} \\
\hline No & 342 & 85.3 & 59 & 14.7 & & \\
\hline
\end{tabular}

Of the total diabetics $52(6.9 \%)$ had hyperlipidemia. .Of this $14(26.9 \%)$ patients had DR. There was significant association between hyperlipidemia and DR.[Table7].

Table-7: Comparison of hyperlipidemia based on retinopathy

\begin{tabular}{|l|l|l|l|l|l|l|}
\hline \multirow{3}{*}{ Hyperlipidemia } & \multicolumn{2}{|l|}{ Retinopathy } & \multirow{2}{*}{} & \multirow{2}{*}{$\chi^{\mathbf{2}}$} \\
\cline { 2 - 5 } & Normal & Abnormal & \multirow{2}{*}{} \\
\cline { 2 - 5 } & Count & Percent & Count & Percent & & \multirow{2}{*}{$6.51^{*}$} \\
\hline Yes & 38 & 73.1 & 14 & 26.9 & 0.011 \\
\hline No & 601 & 86.1 & 97 & 13.9 & \\
\hline
\end{tabular}

*: - Significant at 0.05 level

The incidence of DR was more in uncontrolled diabetics which was significant association at 0.05 level. [Table 8].

Table-8: Comparison of FBS based on retinopathy

\begin{tabular}{|l|l|l|l|l|l|l|}
\hline \multirow{2}{*}{ FBS } & \multicolumn{2}{|l|}{ Retinopathy } & \multirow{2}{*}{} & \multirow{2}{*}{$\chi^{\mathbf{2}}$} \\
\cline { 2 - 5 } & Normal & Abnormal & \multirow{2}{*}{ p } \\
\cline { 2 - 5 } & Count & Percent & Count & Percent & & \\
\hline Normal & 112 & 90.3 & 12 & 9.7 & \\
\hline Moderate control & 171 & 88.1 & 23 & 11.9 & \multirow{2}{*}{0.037} \\
\hline High & 356 & 82.4 & 76 & 17.6 & \\
\hline
\end{tabular}

*: - Significant at 0.05 level 


\section{Discussion}

DR is one of the few ophthalmic diseases that have a defined preventive measure to delay progression of the disease and consequent visual loss.

The reported prevalence of DR varies in different studies. In the Indian scenario ,JS Jain et al at PGI Chandigarh diabetic clinic reported a prevalence rate of 42.9\%. Two other south Indian studies have shown prevalence rate of $34.1 \%$ and $37 \%$ respectively. In the Andhra Pradesh Eye disease study (APEDS) the prevalence rate for DR is $26.2 \%$. The Chennai Urban Rural Epidemiology study (CURES 1) reported a prevalence rate of $17.6 \%$ which is much lower than in other groups [5, 6]. In a study in south India the prevalence of DR in type 2 diabetics in urban India was $10.84 \%$ [7].

In the present study DR was present in $14.8 \%$ of the 750 patients referred for evaluation which is lower compared to most studies. It may be due to racial and demographic factors. However, the methods of detecting retinopathy used in different studies may be the most important reason [8].

Specificity of direct and indirect ophthalmoscopy used in this study to detect retinopathy is high but sensitivity is low (34-50 \%) particularly for early retinopathy. Systematic screening for retinopathy using automated retinal image analysis is emerging as an important screening tool for early detection of DR [9].

In this study a number of risk factors were investigated and it was found that many were significantly related to retinopathy. These included duration of diabetes, hypertension, hyperlipidemia and increased level of fasting blood sugar.

Duration of diabetes and retinopathy are closely associated and this has been proved in a number of previous studies.In the present study the incidence of retinopathy showed a steady increase after 6 years to 20 years $(15.9 \%$ to $35.3 \%)$ and a reduction in incidence after 20 years duration $(17.8 \%)$.

In clinical practice some patients seem to be having a protection against retinopathy despite having multiple risk factors [10]. It is probable that both genetic and environmental factors play a role in the expression of DR $[11,15,16$.$] .$
In this study there was no significant association of hypertension with retinopathy (14.9\%). A number of studies suggest that diastolic blood pressure was related more to the progression than to the occurrence of retinopathy [12]. Studies such as Wisconsin Epidemiological study of diabetic retinopathy (WESDR) and United Kingdom Prospective Diabetes Study (UKPDS) suggest that hypertension increases the risk and progression of DR [11]. This difference in our study may be probably due to good control of hypertension.

The degree of glycemic control proved to be a significant factor in the study ( $\mathrm{p}$ value 0.037 ) consistent with other studies. Glycemic control has been clearly highlighted as a major modifiable risk factor for DR.

Our study showed significant association of hyperlipidemia (Total cholesterol) and retinopathy which is consistent with some studies. In the Chennai urban rural epidemiological study, serum lipids were higher in patients with DR than those without retinopathy $[13,16]$. There are conflicting reports in the literature regarding the effect of lipid profile on retinopathy. Weber et al found that serum triglycerides were strongly associated with degree of retinopathy [14].

\section{Conclusion}

More effort should be given to determine more risk factors for the occurrence of DR in patients with diabetes. Although the present study was able to define many of these factors, much still needs to be done. Awareness about retinopathy, good control of blood sugar, cholesterol and high blood pressure will decrease the incidence of DR.

Funding: Nil, Conflict of interest: None initiated, Permission from IRB: Yes

\section{References}

1. Das A. Diabetic retinopathy: Battling the global epidemic. Indian J Ophthalmol. 2016 Jan;64(1):2-3. doi: 10.4103/0301-4738.178155.

2. Gadkari SS, Maskati QB, Nayak BK. Prevalence of diabetic retinopathy in India: The All India Ophthalmological Society Diabetic Retinopathy Eye 
Screening Study 2014. Indian J Ophthalmol. 2016 Jan;64(1):38-44. doi: 10.4103/0301-4738.178144.

3. Murthy GV, Das T. Diabetic care initiatives to prevent blindness from diabetic retinopathy in India. Indian J Ophthalmol. 2016 Jan;64(1):50-4. doi: 10.4103/0301-4738.178152.

4. Das T Aurora,Chhablani J . Giridhar A,Kumar A, Raman $\mathrm{R}$ et al.Evidence based review of diabetic macular oedema management.Consensus statement on Indian treatment guidelines.Indian J Ophthalmol 2016; 64:14-25

5. M Chakrabarti et al-An effective model for counselling in diabetic patients. Kerala J Ophthalmol 2008; 3:248-251

6. Dr Jay J Meyer et al-Diabetic Retinopathy in Asia :Illumination.Journal of Aravind Eye Care System.Vol V11 No.1 Jan-Mar.2007:15-17 .

7. Namperumalsamy P et al. Prevalence and risk factors for diabetic retinopathy in the population of over 30 years of age in Theni district of South India. Br J Ophthalmol.1999 Aug; 83(8):937-40.

8. Valverde C, Garcia M, Hornero R, Lopez-Galvez MI. Automated detection of diabetic retinopathy in retinal images. Indian J Ophthalmol. 2016 Jan;64(1):26-32. doi: 10.4103/0301-4738.178140.

9. Raman R, Gella L, Srinivasan S, Sharma T. Diabetic retinopathy: An epidemic at home and around the world. Indian J Ophthalmol. 2016 Jan;64(1):69-75. doi: 10.4103/0301-4738.178150.

10. Singh R, Ramasamy K, Abraham C, Gupta V, Gupta A. Diabetic retinopathy: an update. Indian J Ophthalmol. 2008 May-Jun;56(3):178-88.

11. el Haddad OA, Saad MK. Prevalence and risk factors for diabetic retinopathy among Omani diabetics. Br J Ophthalmol. 1998 Aug;82(8):901-6.

12. Cetin EN, Bulgu Y, Ozdemir S, Topsakal S, Akın F, Aybek H, Yıldırım C. Association of serum lipid levels with diabetic retinopathy. Int J Ophthalmol. 2013 Jun 18;6(3):346-9. doi: 10.3980/j.issn.22223959.2013.03.17. Print 2013.

13. Lill.Inger Larsson, Albert Alm,Folke Lithner, Gosta Dahlen and Reinhold Bergstrom:The association of hyperlipidemia with retinopathy in diabetic patients aged 15-50 years in the county of Umea:Acta ophthalmol.scand. 1999;77:585-591.

14. Mishra B, Swaroop A, Kandpal RP. Genetic components in diabetic retinopathy. Indian J Ophthalmol. 2016 Jan;64(1):55-61. doi: 10.4103/03014738.178153.

15. Radha V, Rema M, Mohan V. Genes and diabetic retinopathy. Indian J Ophthalmol. 2002 Mar;50(1):5-11.

16. Kaur P,BBS ,Kaur I,Singh G,Singh B.Correlation of severity of Diabetic Retinopathy with various risk factors.Int J Res Health Sci(internet).2014 Apr $30 ; 2(2): 473-9$.

\section{How to cite this article?}

T. Jayalekshmi, K.P. Poulose. Prevalence of diabetic retinopathy in patients in a tertiary hospital in south India. Int J Med Res Rev 2016;4(10):1802-1806.doi:10.17511/ijmrr. 2016.i10.16. 